\title{
Effect of ballroom dancing on the well-being of cancer patients: Report of a pilot project
}

\author{
THORSTEN SCHMIDT ${ }^{1 *}$, IVONNE RUDOLPH $^{2 *}$, TOBIAS WOZNIAK $^{2 *}$, DANA RUETTERS $^{2 *}$, \\ MARION T. VAN MACKELENBERGH ${ }^{3 *}$ and JUTTA HUEBNER ${ }^{2 *}$ \\ ${ }^{1}$ Cancer Center North, Schleswig-Holstein University Hospital, D-24105 Kiel; \\ ${ }^{2}$ Hematology and Oncology Department, Jena University Hospital, D-04774 Jena; \\ ${ }^{3}$ Clinic of Obstetrics and Gynaecology, Schleswig-Holstein University Hospital, D-24105 Kiel, Germany
}

Received January 9, 2018; Accepted June 8, 2018

DOI: $10.3892 / \mathrm{mco} .2018 .1663$

\begin{abstract}
The present study aimed to evaluate the feasibility of ballroom dancing for patients with cancer and their partners, and develop a simple method for assessing its effects on the patients' well-being. A total of 11 pairs (14 patients and 8 healthy partners) participated. Participation was open, and there were no restrictions in terms of the type of cancer, treatment or comorbidities. An anonymous standardized questionnaire allowing participants to rate their well-being on a visual analogue scale (VAS) from 1 to 10 was used. This rating was repeated at defined time points over 1 week. No adverse events occurred during the study, and the teaching methods appeared to be feasible for the patients. The well-being of all patients remained stable or increased during the class, and returned to the initial level within the following days. A total of 3 patients with a low well-being rating prior to class experienced a strong improvement during the class, which continued until the last day of observation for 2 patients. These results confirm the effectiveness of a VAS-based method for the evaluation of ballroom dancing in patients with different types of cancer undergoing different treatments, and its positive effect on the patients' well-being.
\end{abstract}

\section{Introduction}

Several patients with cancer suffer from extraordinary levels of physical and psychological distress, sleep disturbances and fatigue, and a subsequently reduced quality of life as a

Correspondence to: Dr Thorsten Schmidt, Cancer Center North, Schleswig-Holstein University Hospital, Krebszentrum Nord CCC, Arnold-Heller-Straße 3, Haus 14, D-24105 Kiel, Germany

E-mail: thorsten.schmidt@uksh.de

*On behalf of the Working Group Prevention and Integrative Oncology of the German Cancer Society

Key words: cancer, patients, physical activity, ballroom dancing, sports, well-being result of their medical treatment (1). In a number of previous studies, the positive effects of physical activity on disease- and treatment-associated symptoms, including fatigue, nausea and reduced muscular and cardiovascular performance, have been demonstrated (2-7). Whether it is related to cancer treatment or not, inactivity weakens the skeleton, causes muscle loss and increased adiposity $(8,9)$. A meta-analysis including 49,095 patients with breast and colon carcinoma identified a reduction in the rate of disease recurrence in the patients with a higher activity level (10). While a number of previous studies have focused on biologically based options, such as supplements, others have investigated holistic approaches addressing the body, mind and soul (e.g., mood or well-being) $(11,12)$. Although several cancer patients seek additional methods of improving their quality of life or decreasing the side effects during and after treatment, a significant number of patients do not receive any information regarding the option of physical activity during treatment (13). For this reason, and due to the lack of opportunities for physical activity, cancer patients frequently become inactive during follow-up.

As ballroom dancing is not a new activity for a number of cancer patients, the inhibition threshold and psychological barrier to entry are relatively low. Dance movement therapy may be associated with physical, mental and social benefits, and has been evaluated in a small number of randomized controlled trials (14-18). In these studies, the types of dancing varied, as did the duration and schedule. Data on the improvement of the patients' well-being, physical fitness and fatigue during and after therapy are heterogeneous. In these studies, the patients participated as individuals, either performing as singles or in a group. As the recruitment of patients to participate in a study on dance movement therapy with elaborate assessment appears to be difficult (19), and the participants of the present study objected to assessment with greater detail, a simple approach for evaluation was developed for the study, in order to maximize data collection.

In 2016, a private initiative by three of the authors (IR, TW and $\mathrm{JH}$ ) supported by a foundation started to offer ballroom dance classes for patients and their partners. The primary reason behind the decision to invite partners in addition to patients was the hypothesis that dancing with their partner may offer additional benefits for the patients with respect to 
partnership, body image, and even sexuality. However, this initiative was one of the few to include the partners of patients with cancer.

Ballroom dancing is an activity for which the physical strain may vary from low to a competitive level. Due to the broad range of dance types (standard and Latin American) and music styles included in ballroom dancing, dancing may appeal to patients of any age, including those with a high level and those with a lower level of physical fitness. Furthermore, an important concept of the project was to teach a wide variety of dancing styles to prepare the participants to attend any other event, if so desired, providing the opportunity to pursue further dancing lessons should the pilot be discontinued or should the patient move to another city. As three of the authors (TS, IR, JH) are members of the working group Prevention and Integrative Oncology, the group was asked to develop a simple tool for evaluating the pilot project.

\section{Subjects and methods}

Patient recruitment and lesson format. Participation in the pilot project was open to adults of any age and gender, with any type of cancer, during or after therapy. Each dancing lesson lasted $90 \mathrm{~min}$, with one scheduled pause and individual pauses as required. A class was offered once a week in a community center named 'neighborhood house' in Berlin. The lessons were delivered by a professional dance instructor who had been trained in understanding the basic concepts of cancer diagnosis and treatment, the psychological state and reaction of the patients to the diagnosis, and the possible adverse events that may occur during the class on account of the disease (e.g., fatigue and need for additional pauses, polyneuropathy and difficulty with steps, cognitive dysfunction and difficulties with remembering the last lesson).

As it was unknown whether any complications would arise, in the beginning, each lesson was attended by an oncologist $(\mathrm{JH})$ and a sports scientists with a specialization in rehabilitation and sports medicine (IR) and significant experience in working with cancer patients. Both (JH and IR) are psycho-oncologists. The pilot started in April 2016 and lasted until December 2016. Participation was free of charge, and participants learned about the offer through support groups and an advertisement in the local daily paper. The intensity of the classes was adapted individually; participants who quickly learned the steps of the first few dances and continued to learn new dances and combinations were taught in an advanced group. Participants who required more time for learning were taught in a beginner group. From July onwards the participants in the group remained stable, so the evaluation was implemented in October. In October 2016, a total of 11 pairs attended the lessons. As three pairs were both patients, 14 patients and 8 healthy partners received the questionnaire.

Study evaluation. As the recruitment of patients to a study on dance movement therapy with elaborate assessment tools is difficult (19), it was decided to attempt a stepwise development of the questionnaire, in accordance with the wishes of the participants. After the first session in April, the participants spontaneously remarked that they were highly pleased that an assessment was not required, as they had expected from a course free of charge. We explained that an evaluation was of interest to our group, but that the reluctance of the patients to complete evaluations was established in the literature. The group were asked if they would consent to filling in an anonymous, voluntary and comparably simple questionnaire on their satisfaction with the classes in order to provide feedback, and only one disagreed. The aim was to develop a simple approach of assessment in order to maximize data collection.

For monitoring the impact of the classes on the condition of the participants, an anonymous, standardized questionnaire that recorded demographic data and asked the participants to rate their well-being on a visual analogue scale (VAS) from 1 to 10 was used following initial instructions. This method was selected in accordance with previously described methods for addressing quality of life and well-being, and because VAS are simple to complete and help participants to provide intuitive answers (20). This single question was repeated on a one-sided page for defined time points, including the mean value for the last 3 days, immediately before the lesson, during the break, immediately after the lesson, after the return home, and then every evening up to the next class. Thus, the patients reported how their condition changed before and after the class. Each participant was asked to fill in the questionnaire once daily for an entire week, and return the questionnaire at the next session. Excel 2007 (Microsoft Corporation, Redmond, WA, USA) was used to summarize and visualize the data.

Study ethics. The evaluation of the pilot project was discussed with the Ethics Review Committee in Berlin. In accordance with the regulations of the committee, written ethical approval was not required, as it was not an interventional study and as the evaluation was performed anonymously with a short questionnaire. The participants were informed on the aims of the questionnaire by the class supervisors (IR and JH) and provided their consent by returning the questionnaire.

\section{Results}

Questionnaires. Of the 22 questionnaires distributed, 9 (64\%) were completed by patients and $4(50 \%)$ by their healthy partners (Tables I and II). In total, there were 7 female and 5 male respondents, with the gender of one respondent unspecified (Table III). Among the patients, those with breast cancer constituted the largest group $(n=5)$.

The well-being ratings of the patients and their healthy partners are summarized in Tables I and II. The data were summarized as the arithmetic mean for the patients and partners (Tables I and II). One patient exhibited a deterioration in well-being during the class (no. 7), but returned to the starting level immediately afterwards. For the others patients, well-being remained stable or increased during the class, and returned to the starting level over the following 6 days. Three patients with a low well-being rating in the 3 days before the class $(\geq 5)$ experienced a notable improvement during the class. For all but one healthy partner, the well-being rating increased during the class. This healthy partner (no. 4) exhibited a slight deterioration in well-being during the class, but a strong improvement over the whole evening. In all cases, the well-being rating returned to approximately the starting level over the following days. 
Table I. Well-being of patients over time.

\begin{tabular}{|c|c|c|c|c|c|c|c|c|c|c|c|}
\hline No. & $\begin{array}{c}\text { Last } \\
3 \text { days }\end{array}$ & $\begin{array}{c}\text { Immediately } \\
\text { before }\end{array}$ & $\begin{array}{l}\text { In the } \\
\text { break }\end{array}$ & $\begin{array}{c}\text { Immediately } \\
\text { after }\end{array}$ & $\begin{array}{l}\text { In the } \\
\text { first evening }\end{array}$ & $\begin{array}{c}\text { Day } \\
+1\end{array}$ & $\begin{array}{l}\text { Day } \\
+2\end{array}$ & $\begin{array}{c}\text { Day } \\
+3\end{array}$ & $\begin{array}{l}\text { Day } \\
+4\end{array}$ & $\begin{array}{l}\text { Day } \\
+5\end{array}$ & $\begin{array}{c}\text { Day } \\
+6\end{array}$ \\
\hline 1 & 8 & 9 & 9 & 9 & 9 & 9 & 9 & 9 & 9 & 9 & 9 \\
\hline 2 & 8 & 7 & 8 & 9 & 9 & 9 & 9 & 10 & 9 & 9 & 9 \\
\hline 3 & 9 & 9 & 9 & 10 & 10 & 10 & 9 & 9 & 9 & 9 & 9 \\
\hline 4 & 6 & 7 & 9 & 9 & 9 & 9 & 7 & 8 & 8 & 7 & 6 \\
\hline 5 & 9 & 8 & 10 & 10 & 9 & 9 & 9 & 10 & 10 & 9 & 9 \\
\hline 6 & 6 & 5 & 9 & 9 & 8 & 7 & 8 & 8 & 9 & 7 & 7 \\
\hline 7 & 7 & 8 & 9 & 6 & 8 & 8 & 8 & 9 & 7 & 7 & 8 \\
\hline 8 & 5 & 5 & 8 & 9 & 9 & 9 & 9 & 10 & 9 & 10 & 9 \\
\hline 9 & 3 & 4 & 5 & 5 & 4 & 5 & 4 & 5 & 2 & 3 & 4 \\
\hline $\begin{array}{l}\text { Arithmetic } \\
\text { middle }\end{array}$ & 5.55 & 5.64 & 6.91 & 6.91 & 6.82 & 6.82 & 6.55 & 7.09 & 6.55 & 6.36 & 6.36 \\
\hline
\end{tabular}

1 , very low; 10 , very high.

Table II. Well-being of healthy partners over time.

\begin{tabular}{lcccccccccccc}
\hline No. & $\begin{array}{c}\text { Last } \\
\text { 3 days }\end{array}$ & $\begin{array}{c}\text { Immediately } \\
\text { before }\end{array}$ & $\begin{array}{c}\text { In the } \\
\text { break }\end{array}$ & $\begin{array}{c}\text { Immediately } \\
\text { after }\end{array}$ & $\begin{array}{c}\text { In the } \\
\text { first evening }\end{array}$ & $\begin{array}{c}\text { Day } \\
+1\end{array}$ & $\begin{array}{c}\text { Day } \\
+2\end{array}$ & $\begin{array}{c}\text { Day } \\
+3\end{array}$ & $\begin{array}{c}\text { Day } \\
+4\end{array}$ & $\begin{array}{c}\text { Day } \\
+5\end{array}$ & $\begin{array}{c}\text { Day } \\
+6\end{array}$ \\
\hline 1 & 8 & 9 & 8 & 10 & 9 & 8 & 9 & 9 & 8 & 9 & 9 \\
2 & 5 & 5 & 7 & 9 & 9 & 8 & 7 & 6 & 6 & 6 & 6 \\
3 & 8 & 8 & 10 & 10 & 9 & 8 & 7 & 9 & 9 & 8 & 8 \\
4 & 5 & 5 & 4 & 9 & 8 & 8 & 9 & 9 & 9 & 7 & 6 \\
Arithmetic & 6.5 & 6.75 & 7.23 & 9.5 & 8.75 & 8 & 8 & 8.25 & 8 & 7.5 & 7.25 \\
middle & & & & & & & & & \\
\hline
\end{tabular}

1 , very low; 10, very high.

Adverse events. During all classes, no adverse event occurred. In particular, no cardiovascular problems, aggravation of the side effects of cancer treatment (e.g., nausea), accidents or problems with the musculoskeletal system were observed.

\section{Discussion}

In this pilot project, the feasibility of ballroom dancing classes as a new type of physical activity for cancer patients and their partners was demonstrated. There is a limited number of studies on dance movement therapy for cancer patients in the literature. The types of dancing and the session schedules were heterogeneous. The majority of studies considered younger women with breast cancer and, to the best of our knowledge, no study before the initiation of this pilot offered ballroom dancing in pairs.

In order to reduce the inhibition threshold for access to classes and improve recruitment for the pilot, a flexible and open class schedule was offered, which was adapted to the needs of the patients. On the one hand, this concept makes a rigorous evaluation impossible. In this context, attention must be drawn to the fact that the social desirability of changing condition like the active lifestyle of the patients and the voluntary participation of the patients influenced the data. This bias may also undermine the lack of observed adverse effects, although any serious event during the lessons would have been recorded, as the instructor and at least one physician or sports scientist specialized in rehabilitation and sports medicine attended every lesson. Furthermore, the fluctuation in participation did not allow all participants to be included in the anonymous evaluation. Another limitation of the study, besides the small sample size, the missing control group and the non-detailed assessment, is the heterogeneity of the participating patients e.g., wide age range and different types of cancer (Table III). Due to these limitations, only a trend towards the improvement of well-being for patients and their healthy partners may be derived. This trend is in line with the benefits that have been described in other dance movement therapy programs $(14,15,19)$.

The first randomized study on ballroom dancing was recently published by Pisu et al (21). In that study, participants attended weekly classes and were advised to practice an additional 5 times per week. Several components of quality of life were reported to improve in the patients, but no benefit to the partners was observed. It remains unclear why there 
Table III. Demographic data of all patients and healthy partners.

\begin{tabular}{|c|c|}
\hline Data & No. \\
\hline \multicolumn{2}{|l|}{ Age, years } \\
\hline$<55$ & 0 \\
\hline $56-65$ & 6 \\
\hline $66-75$ & 6 \\
\hline$>75$ & 1 \\
\hline \multicolumn{2}{|l|}{ Gender } \\
\hline Female & 7 \\
\hline Male & 5 \\
\hline No data & 1 \\
\hline \multicolumn{2}{|l|}{ Status } \\
\hline Patient & 9 \\
\hline Healthy partner & 4 \\
\hline \multicolumn{2}{|l|}{ Type of cancer } \\
\hline Breast & 5 \\
\hline Colorectal & 1 \\
\hline Prostate & 1 \\
\hline Melanoma & 2 \\
\hline \multicolumn{2}{|c|}{ Time since first diagnosis, years } \\
\hline$<1$ & 0 \\
\hline$>1$ & 6 \\
\hline$>5$ & 3 \\
\hline \multicolumn{2}{|c|}{ Current cancer therapy } \\
\hline Yes & $5^{\mathrm{a}}$ \\
\hline No & 6 \\
\hline No data & 2 \\
\hline
\end{tabular}

${ }^{\mathrm{a}}$ Chemotherapy $\mathrm{n}=1$, endocrine therapy $\mathrm{n}=2$, interferon $\mathrm{n}=2$.

was no benefit for partners in the previous study, when the partners in the present study reported some improvement in well-being, indicating a benefit. One reason may be the setting of the classes. In the present study, instead of using the rooms of a dance academy, the classes were delivered in community center named 'neighborhood house' where different groups meet. Furthermore, no additional practice or lessons were recommended; the details of other opportunities in the city for dance lessons were instead provided. This respect for the privacy of the patients distinguishes this project from others aiming towards an artistic performance that was prepared and performed by the participants (22).

In a number of previous studies, dancing movements specifically designed for patients with defined disabilities were used. For example, Sandel et al (22) used the 'Lebed Method' for patients with breast cancer, and demonstrated that, aside from general improvements in well-being, the patients' range of arm movements was significantly increased. While specialized forms of dance teaching may effectively address specific disabilities, the more general approach of the pilot project offers the advantage that all patients and partners may be included in one session. For a charity project, this is an impor- tant aspect, as there are numerous opportunities and offers of dance sessions for patients with breast cancer, but only few for patients with prostate or colorectal cancer, and none for patients with rare cancers, in Germany.

As this pilot demonstrated, a short questionnaire based on a VAS may be more easily accepted by the participants. As the questionnaire presents all scales for the different time points one below the other, the participants are provided with an overview of the evolution of their well-being. This direct feedback on their own condition and the impact of the class may increase the patient's motivation for the classes and documentation.

Considering different types of dancing, ballroom dancing may offer certain advantages. In a previous systematic review, 6 controlled studies on other types of dancing were identified, but only one on ballroom dancing (23). Alternatives included dancing as individuals, e.g., line dance or jazz dance, or for pairs, e.g., country dancing, tango Americano and salsa. There were several reasons for the decision to use ballroom dancing in the present study. First, ballroom dancing requires partnership: Each movement is only successful if both partners cooperate, and harmony between the partners improves the effects. In addition, ballroom dancing offers 10 very different dancing styles with a broad range of different movements and styles of music. Accordingly, the probability that the majority of the participants will find dances they like in a course is high. With ballroom dancing, the movement may vary in intensity, allowing the frailer patients to participate. The teacher can vary the tempo of the music, should the group need to slow down. An additional advantage is that ballroom dancing has been previously learned by several patients during adulthood, so there is a basis to build on in teaching. As a consequence, in many cities there are schools and clubs for ballroom dancing where participants can continue their classes by integrating into the regular courses should they move to another town or prefer to leave the special group for patients with cancer.

In conclusion, this pilot project demonstrated that patients with different types of cancer will accept a low-level evaluation of ballroom dancing classes during or after therapy. The classes were also feasible for partners, and both the patient and their partner benefited from this activity. Comparisons between other physical activities and dance classes in further research is important in order to determine whether there are different indications for each.

\section{Acknowledgements}

Not applicable.

\section{Funding}

The Foundation Perspectives for People funded part of the training; however, no funding was received to conduct the study.

\section{Availability of data and materials}

The analyzed data sets generated during the study are available from the corresponding author on reasonable request. 


\section{Authors' contributions}

TS analyzed the data and wrote the article, IR was involved in the data collection and supervised the training, TW and DR designed the training intervention, MvM conducted the statistical analysis and wrote the article, JH made substantial contributions to the design of the present study and wrote the article. All authors read and approved the final manuscript.

\section{Ethics approval and consent to participate}

The project was discussed with the Competent Ethics Review Committee of the state medical chamber at Berlin. Based on their regulations, written ethical approval was not considered necessary as this was not an interventional study, and as evaluation was performed anonymously with a short questionnaire. The participants were informed on the aims of the questionnaire by the authors and provided their consent by returning the questionnaires.

\section{Patient consent for publication}

Written consent was provided by the two patient advocates, Anne Wispler and Siegmund Josten, to publish their names.

\section{Competing interests}

The authors declare that they have no competing interests.

\section{References}

1. Sundaresan P, Sullivan L, Pendlebury S, Kirby A, Rodger A, Joseph D, Campbell I, Dhillon HM and Stockler MR: Patients perceptions of health-related quality of life during and after adjuvant radiotherapy for T1NOM0 breast cancer. Clin Oncol (R Coll Radiol) 27: 9-15, 2015.

2. Baumann FT, Bloch W, Weissen A, Brockhaus M, Beulertz J, Zimmer P, Streckmann F and Zopf EM: Physical activity in breast cancer patients during medical treatment and in the aftercare-a review. Breast Care (Basel) 8: 330-334, 2013.

3. De Backer IC, van Breda E, Vreugdenhil A, Nijziel MR, Kester AD and Schep G: High-intensity strength training improves quality of life in cancer survivors. Acta Oncol 46 : $1143-1151,2007$.

4. Courneya KS, Segal RJ, McKenzie DC, Dong H, Gelmon K, Frieden reich CM, Yasui Y, Reid RD, Crawford JJ and Mackey JR: Effects of exercise during adjuvant chemotherapy on breast cancer outcomes. Med Sci Sports Exerc 46: 1744-1751, 2014.

5. Courneya KS, McKenzie DC, Mackey JR, Gelmon K, Friedenreich CM, Yasui Y, Reid RD, Cook D, Jespersen D, Proulx C, et al: Effects of exercise dose and type during breast cancer chemotherapy: Multicenter randomized trial. J Natl Cancer Inst 105: 1821-1832, 2013.
6. Schmitz KH, Courneya KS, Matthews C, Demark-Wahnefried W, Galvão DA, Pinto BM, Irwin ML, Wolin KY, Segal RJ, Lucia A, et al: American college of sports medicine roundtable on exercise guidelines for cancer survivors. Med Sci Sports Exerc 42: 1409-1426, 2010.

7. Bower JE: Cancer-related fatigue-mechanisms, risk factors, and treatments. Nat Rev Clin Oncol 11: 597-609, 2014.

8. Chlebowski RT: Nutrition and physical activity influence on breast cancer incidence and outcome. Breast 22 (Suppl 2): S30-S37, 2013.

9. Ibrahim EM and Al-Homaidh A: Physical activity and survival after breast cancer diagnosis. Meta-analysis of published studies. Med Oncol 28: 753-765, 2011.

10. Schmid D and Leitzmann MF: Association between physical activity and mortality among breast cancer and colorectal cancer survivors. A systematic review and meta-analysis. Ann Oncol 25: 1293-1311, 2014

11. Bruns F, Büntzel J, Mücke R, Schönekaes K, Kisters K and Micke O: Selenium in the treatment of head and neck lymphedema. Med Princ Pract 13: 185-190, 2004.

12. Huebner J, Prott FJ, Muecke R, Stoll C, Buentzel J, Muenstedt K and Micke O; Prevention and Integrative Oncology of the German Cancer Society Working Group: Economic evaluation of complementary and alternative medicine in oncology. Is there a difference compared to conventional medicine? Med Princ Pract 26: 41-49, 2017.

13. Höh J-C, Schmidt T and Hübner J: Physical activity among cancer survivors-what is their perception and experience? Support Care Cancer 26: 1471-1478, 2018

14. Ho RT, Fong TC, Cheung IK, Yip PS and Luk MY: Effects of a short-term dance movement therapy program on symptoms and stress in patients with breast cancer undergoing radiotherapy. A randomized, controlled, single-blind trial. J Pain Symptom Manage 51: 824-831, 2016.

15. Lemercier L, Bernard P, Delmotte J, Vincent L, Cartron G and Ninot G: Adapted physical activity program (dance) in adults treated by hematopoietic stem cell transplantation: A feasibility study. Oncology 17: 47-56, 2015.

16. Mannheim EG, Helmes A and Weis J: Dance therapy in inpatient oncological rehabilitation. Forsch Komplementmed 20: 33-41, 2013 (In German).

17. Butler M, Snook B and Buck R: The transformative potential of community dance for people with cancer. Qual Health Res 26: 1928-1938, 2016

18. Szalai M, Lévay B, Szirmai A, Papp I, Prémusz V and Bódis J: A clinical study to assess the efficacy of belly dancing as a tool for rehabilitation in female patients with malignancies. Eur J Oncol Nurs 19: 60-65, 2015.

19. Sturm I, Baak J, Storek B, Traore A and Thuss-Patience P: Effect of dance on cancer-related fatigue and quality of life. Support Care Cancer 22: 2241-2249, 2014.

20. Wiskemann J and Scharhag-Rosenberger F: Side effect-oriented exercise therapy pathways of oncological patients. Haug Verlag in MVS Medizinverlage Stuttgart GmbH \& Co. KG Stuttgart 30: 146-150, 2014 (In German).

21. Pisu M, Demark-Wahnefried W, Kenzik KM, Oster RA, Lin CP, Manne S, Alvarez R and Martin MY: A dance intervention for cancer survivors and their partners (RHYTHM). J Cancer Surviv 11: 350-359, 2017.

22. Sandel SL, Judge JO, Landry N,Faria L, Ouellette R and Majczak M: Dance and movement program improves quality-of-life measures in breast cancer survivors. Cancer Nurs 28: 301-309, 2005.

23. Rudolph I, Schmidt T, Wozniak T, Kubin T, Ruetters D and Huebner J; Working Group Prevention and Integrative Oncology of the German Cancer Society: Ballroom dancing as physical activity for patients with cancer. A systematic review and report of a pilot project. J Cancer Res Clin Oncol 144: 759-770, 2018. 